Research Article

\title{
Penerangan Jalan Umum Tenaga Surya: Studi Kasus di Kota Pangkalpinang
}

\author{
Andika Febrianto $^{1}$, Wahri Sunanda ${ }^{1 *}$, Rika Favoria Gusa ${ }^{1}$ \\ ${ }^{1}$ Jurusan Teknik Elektro, Fakultas Teknik, Universitas Bangka Belitung, 33172 \\ *Penulis korespondensi, e-mail: wahrisunanda@gmail.com
}

\begin{abstract}
Abstrak
Penelitian ini dilakukan untuk merencanakan penerangan jalan umum berbasis tenaga surya, didasarkan pada SNI 7391:2008 tentang spesifikasi penerangan jalan di kawasan perkotaan dengan beberapa parameter yang diperhatikan meliputi tiang, lampu yang dipakai, intensitas cahaya yang diperlukan, banyaknya titik lampu yang diperlukan dan peralatan pendukung untuk penerangan jalan umum tenaga surya. Saat ini, jalan Jenderal Sudirman kota Pangkalpinang sepanjang 1,5 km menggunakan penerangan dari PLN dengan 30 unit lampu jenis SON 150 watt dan intensitas cahaya 11 lux. Desain yang didapatkan untuk penerangan jalan umum tenaga surya memperhatikan SNI untuk intensitas cahaya. Pada akhir penelitian didapatkan peralatan pendukung penerangan jalan umum tenaga surya yakni 31 tiang octagonal 8 meter dengan tiap satu stang ornamen pada tiap tiang memerlukan 1 unit lampu LED 40 watt, 1 unit panel surya $100 \mathrm{Wp}, 1$ unit baterai VRLA 100 Ah dan 1 unit solar charger controller $(10 \mathrm{~A}, 12 \mathrm{~V} / 24 \mathrm{~V})$.
\end{abstract}

Kata Kunci: perencanaan penerangan jalan umum, jalan umum berbasis tenaga surya, Standar Nasional Indonesia

\begin{abstract}
This research was conducted to design public street lighting photovoltaic, based on SNI 7391:2008 concerning specifications of public street lighting in urban areas with several parameters that were considered by poles, lights used, intensity of light needed, number of lights needed and supporting equipment for public street lighting photovoltaic. Currently, Jenderal Sudirman road in the city of Pangkalpinang along $1.5 \mathrm{~km}$ uses electricity from PLN with 30 units of 150 watt SON lamps and 11 lux light intensity. The design obtained for street lighting photovoltaic while still meet SNI for light intensity, obtained supporting equipment for solar street lighting, namely 31 unit of 8 meter octagonal poles with specifications of 40 watt LED lights for each cross arm, 1 unit of 100 Wp solar panels, unit of 100 Ah VRLA batteries and 1 unit of solar charger controller $(10 \mathrm{~A}, 12 \mathrm{~V} / 24 \mathrm{~V})$.
\end{abstract}

Keywords: public street lighting planning, public street lighting photovoltaic, Indonesia's National Standart

\section{Pendahuluan}

Transportasi merupakan salah satu faktor penting dalam memperlancar kegiatan perekonomian suatu kota. Oleh karena itu, jalan sebagai prasarana utama dalam perhubungan darat harus diperhatikan kondisi dan penggunaannya. Berdasarkan data BPS tahun 2017, kota Pangkalpinang memiliki panjang jalan sepanjang 356,33 km, dimana 94,95 persen dari total jalan sudah dilapisi aspal. Berdasarkan kondisi 
jalan 73,70 persen digolongkan baik, sedangkan sisanya dalam keadaan rusak. Dinas Pendapatan, Pengelolaan Keuangan dan Aset Daerah Kota Pangkalpinang mencatat bahwa terdapat 20.391 kendaraan roda empat yang telah membayar pajak pada tahun 2016. Jumlah tersebut didominasi oleh bus, yaitu sebanyak 12.273 bus. Sedangkan untuk kendaraan roda dua mencapai 57.057 unit sepeda motor.

Penerangan jalan umum harus memenuhi standar SNI 7391:2008, mengenai Spesifikasi Penerangan Jalan di Kawasan Perkotaan karena bertujuan untuk mendapatkan keseragaman dalam merencanakan penerangan jalan khususnya di kawasan perkotaan. Sehingga, penerangan jalan yang dapat memberikan keselamatan, kelancaran, dan kenyamanan bagi pengguna jalan dapat direncanakan dan disediakan oleh pemerintah. Saat ini, jalan umum menerapkan sistem penerangan lampu jalan dengan menggunakan lampu jenis sodium, dan bersumber dari sistem kelistrikan PLN (Perusahaan Listrik Negara). Lampu sodium memiliki kekurangan, yaitu besarnya daya yang digunakan apabila dibandingkan jenis lampu LED dengan luminansi yang sama.

Beberapa artikel terkait diantaranya Sihombing (2013) yang mendapatkan hasil bahwa penerangan jalan umum menggunakan sumber PLN memiliki konsumsi daya yang lebih besar jika dibandingkan dari bersumber dari PLTS yakni 76,6\% dan 23,3\%. Aung (2014) mendapatkan fakta bahwa kapasitas panel photovoltaic yang digunakan untuk penerangan jalan akan menentukan spesifikasi dan desain LED yang akan digunakan. Sementara ,itu Escolar (2015) melakukan penelitian untuk meningkatkan kualitas penerangan jalan sebagai bagian dari kebijakan Pemerintah Spanyol untuk menurunkan konsumsi energi listrik. Anhar (2018) menyatakan bahwa penelitiannya untuk lampu jalan menggunakan lampu dc 12 volt, panel surya $50 \mathrm{Wp}$, charge control 10 A, battery 65 Ah dapat digunakan selama 12 jam. Untuk desain yang paling ekonomis dari beberapa konfigurasi sistem photovoltaic adalah dengan pembebanan 20\% (Sunanda, 2018). Penelitian ini sendiri bertujuan untuk merencanakan desain penerangan jalan berbasis tenaga surya, dengan tetap memperhatikan standar penerangan nasional dan menuju target pengurangan penggunaan energi fosil dalam jangka waktu yang panjang.

\section{Metode Penelitian}

Tahap pengambilan data sekunder dan tahap pengukuran data primer meliputi pengambilan data lebar jalan, panjang jalan, luminansi lampu, dan data penyinaran matahari di lokasi sampel penelitian. Kemudian, parameter standar dihitung untuk spesifikasi jalan yang ada sesuai dengan SNI 7391:2008 (tiang, lampu yang dipakai, intensitas cahaya yang diperlukan serta banyaknya titik lampu yang diperlukan) serta menghitung jumlah komponen penerangan jalan umum tenaga surya yang dibutuhkan seperti kebutuhan dari panel dan baterai.

a. Data lebar dan panjang jalan

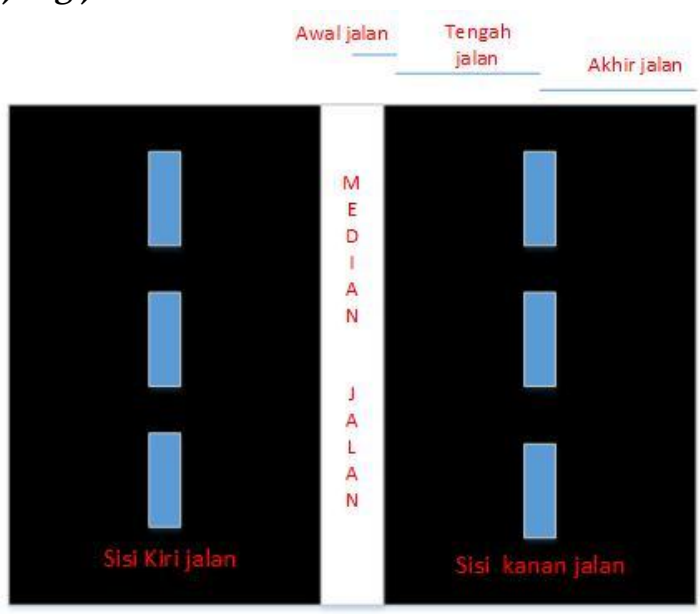

Gambar 1. Pengukuran Lebar Jalan 


\section{b. Data luminansi lampu}

Pengukuran luminansi lampu dilakukan pada malam hari dengan menggunakan lux meter dimulai pukul oo.oo wib sampai 02.0o wib. Selama 2 hari lampu yang diukur sebanyak 6o unit.

\section{c. Pengukuran penyinaran matahari}

Data penyinaran matahari diperoleh dengan cara pengukuran menggunakan alat ukur solar power meter. Pengukuran dimulai pada pukul o9.oo pagi sampai pukul 14.30, dilakukan setiap 30 menit secara tegak lurus.

\section{Hasil dan Pembahasan}

\subsection{Penerangan Jalan Umum (PJU) yang Terpasang di Jalan Jendral Sudirman}

Jalan Jendral Sudirman yang merupakan jalan arteri primeri (jalan nasional) dimana kondisi eksisting di jalan ini sudah memiliki penerangan jalam umum (PJU) dengan tinggi tiang $8 \mathrm{~m}$ panjang stang ornamen 2,5 meter, kabel yang di gunakan adalah tipe kabel NYM $2 \times 16 \mathrm{~mm}$, yang terpasang di udara. Untuk lampu PJU yang menggunakan kabel udara terletak di jalur dua di depan Kantor Bank BRI Cabang Pangkal Pinang, sampai perempatan lampu lalu lintas Ramayana, sepanjang 765 meter. Dari perempatan lampu lalu lintas Ramayana, sampai perempatan lampu lalu lintas Semabung, menggunakan jenis kabel bawah tanah sepanjang 735 meter. Jenis lampu menggunakan lampu SON 150 watt, dan jarak antar tiang 50 meter. Sistem yang digunakan untuk menghidupkan lampu tersebut adalah dengan mengunakan energi listrik yang diatur oleh theben (timer) sehingga secara otomatis pada waktu tertentu lampu akan menyala.
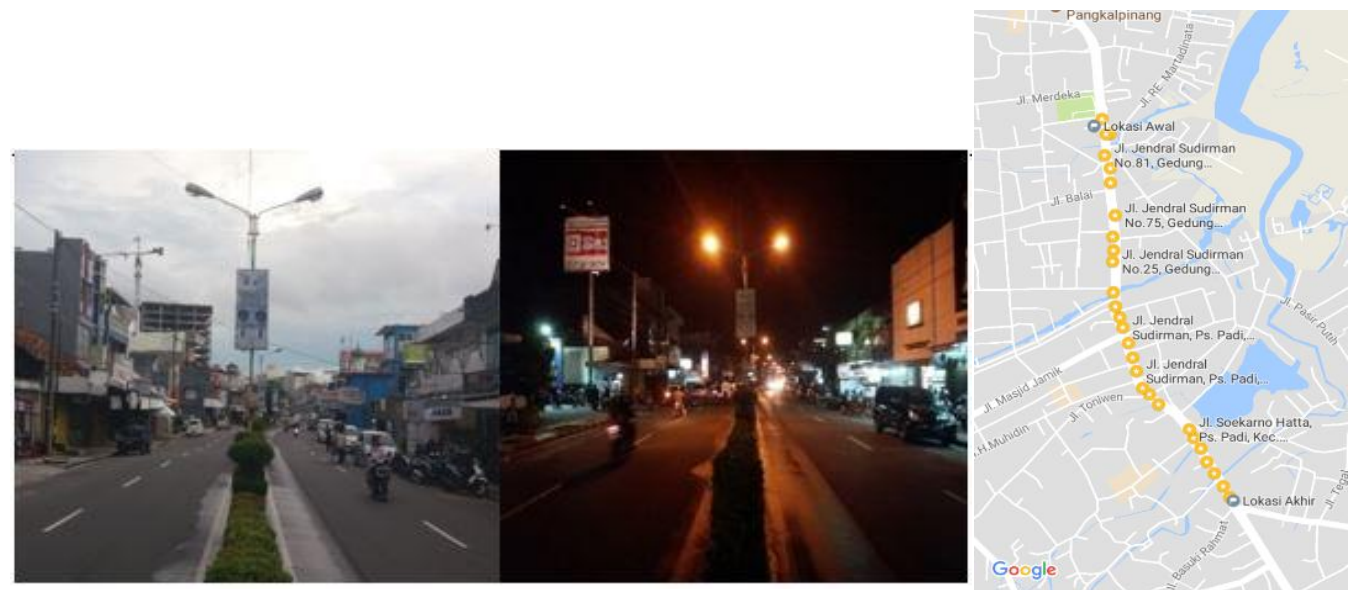

Gambar 2. Kondisi Siang Hari (kiri) dan Malam Hari (tengah) Jalan Protokol, serta Titik - Titik Pengukuran PJU di Kota Pangkalpinang

Menurut SNI 7391:2008 kondisi lampu penerangan jalan di malam hari harus berada pada nilai rata-rata 11-20 lux. Penerangan Jalan Umum (PJU), yang terdapat di jalan Jendral Sudirman masih ada 6 unit lampu PJU yang masih memiliki kuat pencahayaan (iluminansi) dengan nilai rata- rata kurang dari 11 lux. Dari 30 unit PJU yang diukur, terdapat 6 unit PJU dalam kondisi yang tidak baik seperti lampu rusak dan kondisi stang ornamen yang tidak sesuai dengan penempatan awal, sedangkan 24 unit PJU dalam kondisi baik dan nilai pengukuran rata-rata diatas 11 lux.

\subsection{Lampu PJU}

Dalam penelitian ini, perencanaan awal dilakukan untuk memperbaiki sistem penerangan jalan umum yang berlokasi di Jalan Jendral Sudirman sampai jalan Mayor Syafri Rahman yang memiliki 30 unit penerangan jalan umum dengan panjang total jalan 1,5 kilometer. Gambar 3 merupakan contoh gambar desain perencanaan penerangan jalan umum. 


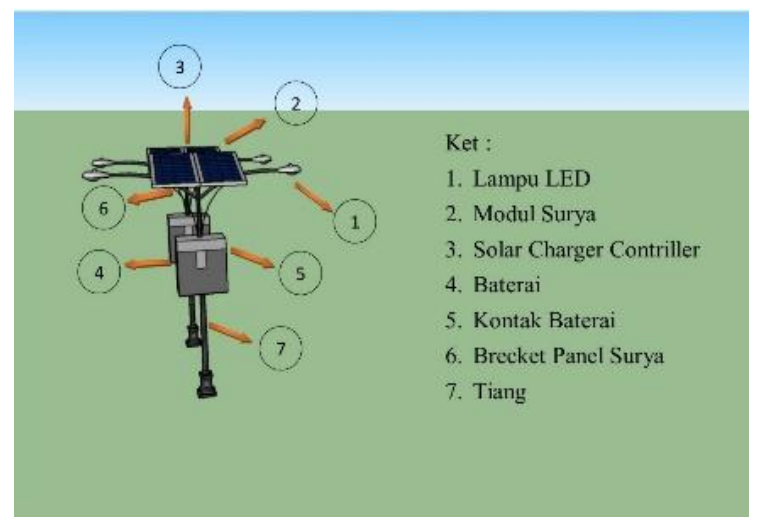

Gambar 3. Komponen PJU berbasis tenaga surya

Gambar 3 menjelaskan bahwa satu unit komponen penerangan jalan umum dengan pembangkit listrik tenaga surya terdiri dari lampu LED, panel, solar charger controller, baterai, bracket panel surya, dan tiang.

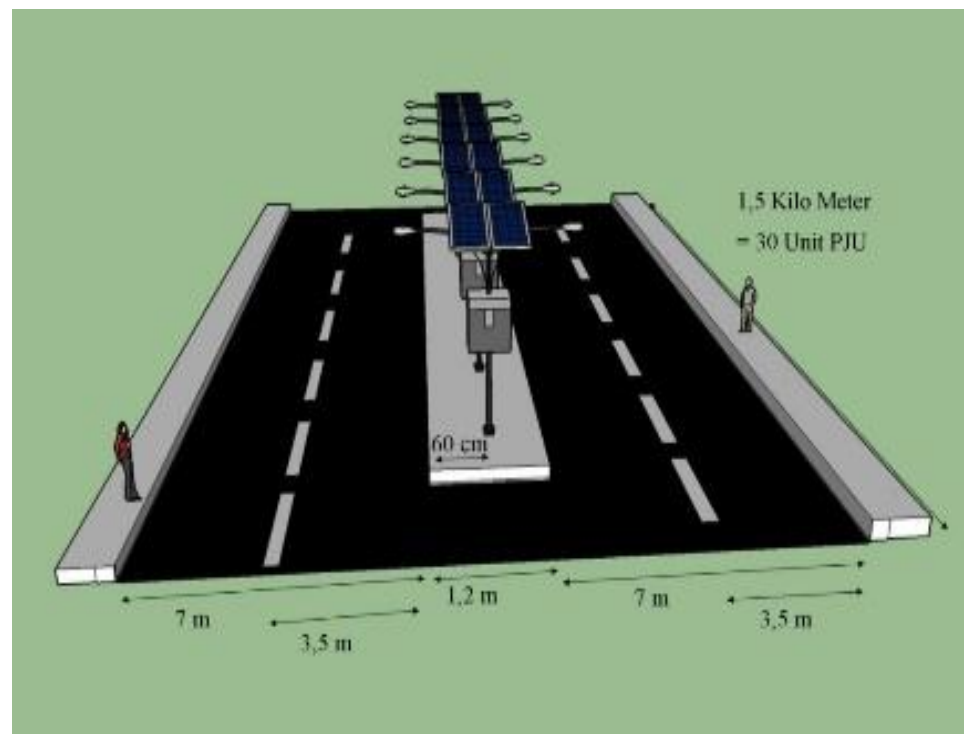

Gambar 4. Total Ukuran Panjang PJU

Pada Gambar 4, digambarkan 30 unit PJU yang tersusun dengan panjang 1,5 kilometer didesain mengikuti ukuran lebar jalan yang sudah dihitung sebelumnya menggunakan meteran sehingga jarak dan pencahayaan yang dihasilkan akan sesuai dengan perhitungan.

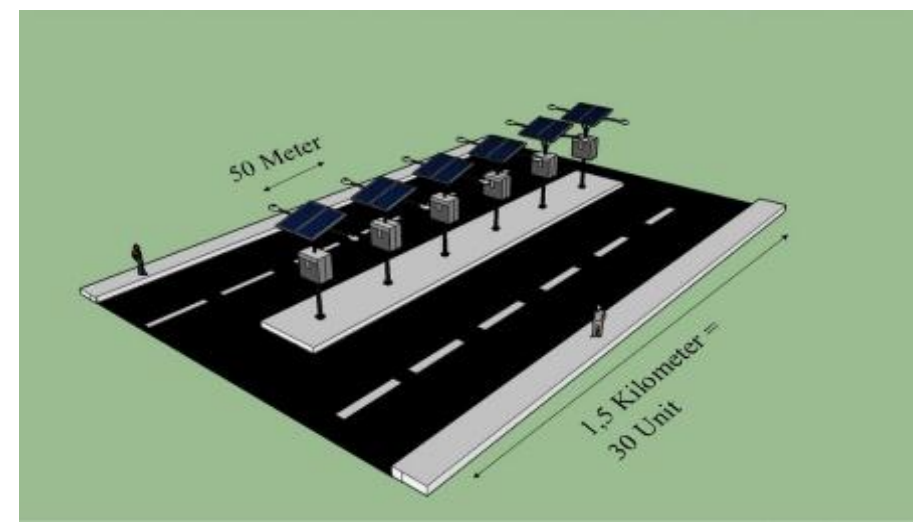

Gambar 5. Jarak antar tiang unit PJU 
Pada Gambar 5 dapat dilihat bahwa jarak antar tiang lampu PJU adalah 50 meter. Jarak tersebut didapatkan berdasarkan hasil rata-rata pengukuran lampu PJU yang terdapat di ruas jalan kota Pangkalpinang.

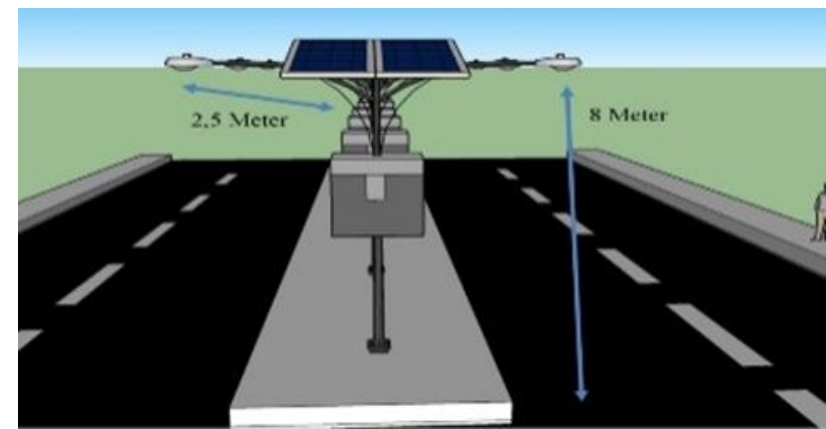

Gambar 6. Ukuran Ketinggian Tiang dan Stang Ornamen PJU

Pada Gambar 6 diketahui bahwa ukuran ketinggian tiang PJU telah disesuaikan dengan kondisi badan jalan di jalan Jendral Sudirman. Agar tidak mengenai mobil yang berukuran besar, stang ornamen dipasang setinggi 8 meter dari permukaan tanah.

\subsection{Tiang Lampu}

Jalan Jendral Sudirman memiliki penerangan jalan umum dengan tinggi tiang oktagonal $8 \mathrm{~m}$ dengan jenis lampu tipe SON 150 watt. Panjang stang ornamen 2,5 $\mathrm{m}$ dan jarak antar tiang $50 \mathrm{~m}$. Untuk perencanaan lampu penerangan jalan umum dengan tenaga surya menggunakan jenis tiang yg sama dan dengan menggunakan 2 stang ornamen. Dengan sudut kemiringan stang ornamen 1,3 meter, didapatkan jarak lampu ke tengah-tengah jalan yakni 8,105 meter.

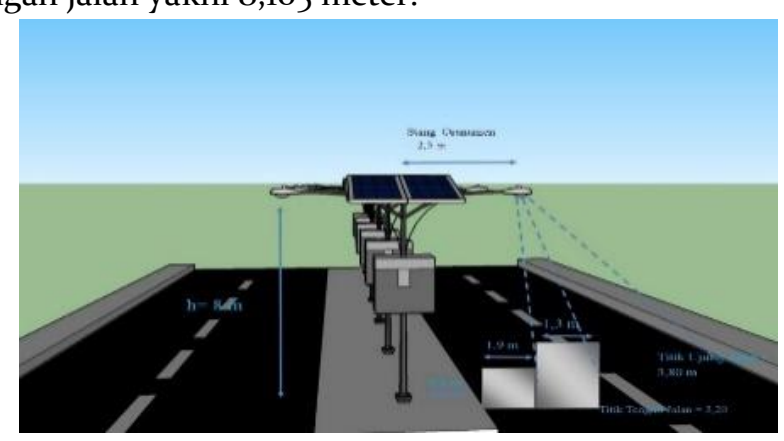

Gambar 7. Pengukuran Lampu PJU

\subsection{Intensitas Cahaya}

Dengan jarak lampu ke ujung jalan 9,487 meter, didapatkan nilai intensitas cahaya 20,09 lux. Nilai intensitas cahaya masih dalam rentang yang memenuhi syarat untuk jalan arteri primer sesuai SNI 7391:2008. Dengan nilai intensitas cahaya sebesar 1831,92 Cd (dalam satuan SI), daya nominal LED yang digunakan adalah sebesar 40 watt.

\subsection{Jumlah Titik Lampu yang Diperlukan}

Dalam perencanaan ini ditetapkan jarak antar tiang (s) sepanjang $50 \mathrm{~m}$ sehingga jumlah titik lampu yang diperlukan sejumlah 31 tiang.

\subsection{Perencanaan Penerangan Jalan Umum Tenaga Surya (PJUTS)}

Dalam perencanaan PJUTS di sepanjang jalan Jendral Sudirman dibutuhkan data rata - rata penyinaran matahari dan suhu agar daya yang dihasilkan dan jumlah panel yang harus disiapkan sesuai dengan sistem yang dibutuhkan. Lamanya penyinaran matahari dalam 1 hari diukur selama 5 jam dimulai pada pukul o9.0o sampai dengan 14.30. Besar rata - rata pemakaian energi listrik harian di jalan Jendral 
Sudirman adalah $960 \mathrm{Wh} /$ hari. Untuk nilai energi radiasi surya di Pangkalpinang rata-rata $4.95 \mathrm{kWh} / \mathrm{m}^{2}$ (Yuant, 2019). Nilai $\eta P V$ adalah nilai dari efisiensi panel surya sebesar $14,78 \%$ dan untuk nilai $\eta$ output dihitung berdasarkan efisiensi komponen - komponen yang melengkapi sistem PJUTS. Sistem dilengkapi dengan baterai dan solar charger controller $\eta$ output adalah hasil perkalian dari keseluruhan efisiensi komponen baterai dan solar charger controller 0,792. Suhu standar untuk panel surya dapat bekerja dengan baik pada suhu $25^{\circ} \mathrm{C}$ dan suhu maksimal kota Pangkalpinang menurut Badan Meteorologi, Klimatologi dan Geofisika Pangkalpinang sebesar $32^{\circ} \mathrm{C}$. Sehingga akan terjadi perubahan daya yang dihasilkan disaat suhu yang diterima panel surya mengalami perubahan. Untuk daya keluaran maksimum panel surya pada saat temperatur naik menjadi $32^{\circ} \mathrm{C}$ yakni 115,8 . Dengan Temperature Correction Factor (TCF) 0,965 dan pemakaian konsumsi energi listrik 96o Wh/hari (untuk total konsumsi energi di 2 stang ornamen pada 1 tiang lampu) didapat $\mathrm{PV}$ area $\mathrm{o}, 01 \mathrm{~m}^{2}$. Untuk nilai area sebesar o,o1 $\mathrm{m}^{2}$, PSI ( Peak Sun Insolation ) adalah $1000 \mathrm{~W} / \mathrm{m}^{2}$ dan efisiensi panel surya sebesar $14,78 \%$, maka didapat $\mathrm{P}$ watt peak 147,8 watt dengan panel yang diperlukan untuk PLTS yang direncanakan berjumlah 2 unit. Perhitungan dilakukan sebagai pendekatan untuk mengetahui besarnya kebutuhan panel yang seharusnya disiapkan sehingga biaya yang dikeluarkan untuk modal panel dapat ditentukan. Jadi, hasil perhitungan menunjukkan bahwa daya listrik yang dibangkitkan adalah 147,8 watt kemudian dibagi dengan daya output panel sebesar 100 watt. Hal ini menunjukkan bahwa jumlah panel yang dibutuhkan adalah sebanyak 2 unit per 1 tiang lampu.

\subsection{Perencanaan Baterai}

Pada perencanaan sistem berbasis tenaga surya dibutuhkan sumber tenaga yang berguna untuk menyimpan energi listrik agar dapat digunakan pada waktu tertentu sehingga daya listrik yang dihasilkan dapat digunakan secara langsung ataupun tersimpan pada baterai. Pada perencanaan ini, digunakan sumber listrik berupa aki kering berkapasitas 100 Ah dengan tegangan 12 volt. Kebutuhan baterai setelah mempertimbangkan hari otonomi atau hari - hari tanpa matahari (tidak bisa terkena sinar matahari karena efek cuaca) selama 2 hari berturut - turut untuk 1 unit lampu dengan daya 40 watt, sebesar $100 \mathrm{Ah}$. Keunggulan tipe aki VRLA salah satunya tidak memerlukan perawatan rutin sehingga dari segi ekonomis dapat menghemat dalam perancangan dan memiliki life time yang lebih lama dan dapat mengurangi kuantitas pengantian unit pada aki sehingga dari segi ekonomis accumulator / aki ini lebih menguntungkan untuk menekan biaya modal pada sistem PJUTS. Untuk memenuhi kebutuhan listrik di PJU jalan Jendral Sudirman yang beroperasi pada malam hari, dibutuhkan 1 unit acumulator / aki untuk 1 unit lampu 40 watt LED.

\section{Kesimpulan}

Dari hasil penelitian didapatkan kesimpulan bahwa sistem penerangan di jalan Jendral Sudirman masih menggunakan sistem yang terhubung dengan jaringan PLN terdiri 30 unit PJU jenis SON 150 watt dengan intensitas cahaya 11 lux. Sistem penerangan jalan jika menggunakan tenaga surya menggunakan 31 tiang octagonal 8 meter, dengan satu stang ornamen pada tiap tiang dibutuhkan 1 unit LED 40 watt, panel surya 1 x $100 \mathrm{Wp}, 1$ unit baterai VRLA 100 Ah dan 1 unit solar charger controller $(10 \mathrm{~A}, 12 \mathrm{~V} / 24 \mathrm{~V})$.

\section{Daftar Pustaka}

Anhar, W., Basr, Amin, M., Randis., Sulistyo, T. 2018. Perhitungan Lampu Penerangan Jalan Berbasis Solar System. Jurnal Sains Terapan. Vol 4. No. 1 (hal. 33-36). Balikpapan.

Aung, N.S.M., Myint, Z.H., 2014. Design of Stand Alone Solar Street Lighting System with LED. International Journal of Scientific Engineering and Tehnology Research Vol. 3 No. 17., pp. 3518 3522.

Escolar, A.G., Martinez, A.C., Pulido, J.M.G., et al., 2015. A Study to Improve the Quality Street Lighting in Spain. Journal Energies 8 pp. 976-994. 
Sihombing, D.T.B., Kasim, S.T., 2013. Perencanaan Sistem Penerangan Jalan Umum dan Taman di Areal Kampus USU dengan Menggunakan Teknologi Tenaga Surya (Aplikasi di Areal Pendopo dan Lapangan Parkir). Jurnal Singuida Ensikom Vol. 3. No. 3 (hal. 118-123). Medan

Sunanda, W.,. 2018. Home Photovoltaic System Design in Pangkalpinang City. E3S Web Conf. 3102006

Tiandho, Y., Sunanda, W., Gusa, R.F., Dinata, I., Novitasari, D. 2019. Solar Energy Potential in Bangka Belitung Islands, Indonesia. IOP Conf. Ser.: Earth Environ. Sci. 257012022

2017., Jalan Jendral Sudirman Kota Pangkalpinang, diakses pada 13 September 2017, http://map.google.co.id.

2017., Kondisi Jalan Pangkalpinang. BPS Babel.

2016., Data DPPKAD Kota Pangkalpinang.

2008., SNI 7391 Spesifikasi Penerangan Jalan di Kawasan Perkotaan. 